\title{
Information and communication technology use in asthmatic patients: a cross-sectional study in Latin America
}

\author{
Juan Calderón (10), ${ }^{1,2}$ Annia Cherrez ${ }^{1,3}$, Germán Darío Ramón ${ }^{4}$, Orlando Lopez \\ Jove $^{5}$, Alan Baptist ${ }^{6}$, Edgar Matos ${ }^{7}$, Blanca Morfín Maciel ${ }^{8}$, Erick Calero ${ }^{1,2}$, \\ Mario Sanchez-Borges ${ }^{9}$, Sofia Cherrez ${ }^{1,3}$, Daniel Simancas-Racines ${ }^{10}$ and \\ Ivan Cherrez Ojeda ${ }^{1,2}$
}

Affiliations: ${ }^{1}$ Respiralab, Respiralab Research Group, Guayaquil, Ecuador. ${ }^{2}$ Universidad Espiritu Santo, Samborodon, Ecuador. ${ }^{3}$ School of Medicine, University of Heidelberg, Heidelberg, Germany. ${ }^{4}$ Allergy Section, Hospital Italiano Regional del Sur, Bahía Blanca, Argentina. ${ }^{5} \mathrm{Dr}$ A. Cetrángolo Hospital, Pulmonary Laboratory Dept, Vicente López, Argentina. ${ }^{6}$ University of Michigan, Dept of Internal Medicine, Ann Arbor, MI, USA. ${ }^{7}$ Instituto Nacional de Salud del Nino, Lima, Peru. ${ }^{8}$ Hospital Angeles Mocel, Mexico City, Mexico. ${ }^{9}$ Centro Medico Docente La Trinidad, Caracas, Bolivarian Republic of Venezuela. ${ }^{10}$ Universidad Tecnologica Equinoccial, Quito, Ecuador.

Correspondence: Ivan Cherrez Ojeda, Universidad de Especialidades Espiritu Santo, School of Medicine, Samborondon Highway, Samborondon 09112, Ecuador. E-mail: ivancherrezlagmail.com

ABSTRACT Rapid diffusion, low cost and broad availability of information and communication technologies (ICTs) make them an attractive platform for managing care, communication and interventions in asthma. There is little information in Latin America about usage frequency of ICTs in asthmatic patients.

The analysis undertaken consisted of an observational, cross-sectional study that aimed to identify the frequency and type of ICTs most often used by asthmatics. The Spanish version of the Michigan questionnaire was employed in five Latin American countries. Age and educational level was categorised. Logistic regression was performed among these groups concerning the frequency of ICT usage and the level of interest shown in seeking and receiving information about asthma.

In total, 673 asthma patients were surveyed. The mean age was 43.44 years. Over two-thirds of the participants were female (68.4\%). The most used ICT was the short message service (SMS) (69.9\%). SMS and E-mail are useful tools for communicating (i.e. receiving and seeking information) with all asthma patients, irrespective of their age. WhatsApp (61.5\%) and Facebook $(32.0 \%)$ were rated as being the most interesting channels of communication for receiving information. Regression analysis showed that younger asthmatics and asthmatics with higher educational levels were most likely to use almost all forms of ICTs.

ICTs are generally an attractive platform for managing care, communication and interventions to improve asthma care. SMS and E-mail were found to be the preferred ICT forms among users. However, social media forms such as WhatsApp and Facebook may also be appropriate for certain types of patient.

@ERSpublications

ICT and social media use among asthmatics from Latin America http://ow.ly/TxVj30cKylJ

Cite this article as: Calderón J, Cherrez A, Ramón GD, et al. Information and communication technology use in asthmatic patients: a cross-sectional study in Latin America. ERJ Open Res 2017; 3: 00005-2017 [https://doi.org/10.1183/23120541.00005-2017].

This article has supplementary material available from openres.ersjournals.com

Received: Jan 062017 | Accepted after revision: May 312017

Support statement: This study was partially supported by an unrestricted grant from the Universidad de Especialidades Espíritu Santo. The sponsor had no role in the design of the study or in the collection, analysis and interpretation of data.

Conflict of interest: None declared.

Copyright $\odot$ ERS 2017. This article is open access and distributed under the terms of the Creative Commons Attribution Licence 4.0. 


\section{Introduction}

In recent decades, the number of patients suffering from asthma and asthma-related conditions has risen around the world. The number of people with asthma has increased by $2.9 \%$ each year [1]. In Latin America, the prevalence of physician-diagnosed asthma in children varies widely, ranging from $8.7 \%$ in Mexico to $30.8 \%$ in El Salvador [2]. In contrast, the prevalence of asthma sufferers among Latin American adults has been estimated to stand at $5-6.3 \%[3,4]$. The increase in the rates of asthma sufferers in developed countries has raised concerns about the considerable burden - both societal and individual - of this disease. New strategies to improve clinical outcomes and to encourage good communication between healthcare providers and patients are now being explored, giving rise to a heightened interest in the use of information and communication technologies (ICTs) for medical purposes [5-7].

ICTs are broadly defined as technologies used to communicate, manipulate and store data by electronic means. This includes E-mail, short message service (SMS) text messaging, video chat (i.e. Skype or Hangouts) and online social media (i.e. Facebook or Twitter) as well as all the different computing and mobile-type devices (smartphones and tablets) that perform a wide range of communication and information functions [8]. ICTs have seen dramatic increases in usage over the past decade, particularly among adolescents and young adults $[9,10]$. Several studies have suggested that the use of ICTs in general may have a positive effect on asthma patients by facilitating communication between healthcare professionals and patients as well as by helping patients learn more about their day-to-day care [11]. In a publication assessing the frequency of ICT usage in asthma patients, E-mail was the most used ICT, while text messaging and social media sites such as Facebook were considered appropriate for younger patients [12].

The successful and widespread use of ICTs has the potential to allow asthmatics who may feel stigmatised by their illness to contact people with similar symptoms and share their struggles and triumphs. To this end, software developers have created mobile applications (i.e. apps) that have penetrated people's daily lives and are increasingly accepted as tools to support self-management for people with chronic diseases. In fact, a recent meta-analysis found that mobile apps have the potential to be highly effective in supporting self-management, especially those apps that incorporate an asthma action plan, and they may be preferred by some people and their physicians over more conventional approaches. It should be noted, however, that such communication technologies have an inconsistent impact on asthma control and quality of life [13]. Indeed, many people stop using healthcare apps shortly after downloading them. These findings suggest that app developers need to address consumer concerns better and that clinical trials are necessary to test the efficacy of health apps to broaden their appeal and widen their use [14-16].

At present, it is not known how patients and healthcare practitioners can identify good-quality and appropriate applications for managing asthma care and communication. There is insufficient evidence when it comes to the best use of smartphones, tablets or computer apps in asthma self-management programmes $[17,18]$. Evidence is also scarce regarding identifying the important features that attract and encourage patients to continue using a particular application. The lifespans of such applications vary considerably, because many were developed without considering the method preferred by patients for obtaining information and enquiring confidentially and constructively about their disease. An enhanced understanding of such patient preferences regarding ICTs should facilitate the development of applications that can best improve asthma outcomes.

The aim of the present study was to assess the frequency of ICT usage and preferences among patients with asthma. The results should assist in the development of new personal ICT applications, promote the relationship between the patient and healthcare provider, and ultimately improve asthma care and medical outcomes.

\section{Materials and methods Study design}

We conducted an anonymous cross-sectional survey in which asthmatic patients from Latin America answered questions that asked them to rate themselves in accordance with their typical frequency of ICT usage. Eligible outpatients were from public or private practices in Guayaquil (Ecuador), Buenos Aires (Argentina), Mexico City (Mexico), Lima (Peru) and Caracas (Venezuela) [12]. The survey was composed of 18 items and collected information about demographics, use of cellphones, the interest of patients in using ICTs to receive information about asthma, and the interest of patients in using ICTs to communicate with healthcare providers about asthma.

The inclusion criteria for this survey were as follows: patients were more than 12 years old and had received an asthma diagnosis at least 1 year earlier than the carrying-out of the survey. We excluded patients with psychiatric diseases, language impairment or who found it difficult to visualise the survey. 


\section{Procedures}

We used the Michigan questionnaire, which was developed in the USA. This questionnaire assesses the frequency of use of ICTs in asthmatic patients and evaluates how they prefer to receive information about their disease [12]. We used a rigorous methodology and a translated version of the questionnaire [19].

We collected demographic information about each patient, including age, sex and race/ethnicity, together with information about the patient's duration of time with asthma (i.e. time since diagnosis) and the use of asthma medication. Participants were then asked to quantify their use of each technology (text messaging, Facebook, Twitter, Myspace, E-mail, LinkedIn, YouTube, Skype and the Internet), using a scale of daily, at least once a week, at least once a month, less than once a month, or never.

Participants were also asked to quantify their interest in receiving information about factors that could affect asthma control through each technology (e.g. pollen count, ozone level, medication reminders, asthma tips). Level of interest was quantified as high, somewhat, low, or no interest. Using the same scale, participants were asked to quantify their interest in directing questions to their doctors or other healthcare providers using each of the ICT forms. Free text entries were solicited to determine what information participants would most like to receive via these technologies, the reasons they might not be interested in using such technologies for communication, and any other comments about the use of these methods for asthmatic patients.

We incorporated a new question into the survey relating to patients' frequency of use of WhatsApp. This question was included because it was highly relevant to our study, but not included in the original questionnaire. We asked participants whether they were interested in seeking and receiving information about asthma using WhatsApp. The dichotomised answer was "yes" or "no".

Before answering the Michigan questionnaire, patients were informed of the purpose of the study and their role in it. During the survey, patients completed their questionnaires either by themselves or with the help of a previously trained person (e.g. physician, nurse or intern).

\section{Ethical considerations}

This study was approved by the Ethics Committee of the Hospital Luis Vernaza, Ecuador. We obtained informed consent before participation in the survey. We guaranteed that the identity of the patient would not be revealed.

\section{Statistical analysis}

For each ICT type we dichotomised the answers into categories of "at least once a week" or "less than once a week". Age was categorised into young (12-18 years), adults (19-40 years) and old adults (>40 years). Education level was categorised into none or elementary school, high school and university or postgraduate. The span of time since asthma diagnosis was categorised as $\leqslant 5$ years and $>5$ years.

We used a chi-squared test to assess the association between Internet access or owning a cell or smartphone and age, sex, educational level and number of years since diagnosis. We used the same test to assess the association between the independent variables previously introduced and the frequency of use of each ICT type (SMS, Facebook, Twitter, YouTube, E-mail, Internet, LinkedIn and Skype) as well as level of interest (high or some interest) in receiving and seeking information (i.e. directing questions to the practitioner) through such ICTs.

We performed adjusted regression analyses between categories of age, sex, educational level, years since diagnosis and the use and level of interest shown in communicating through ICTs. Finally, non-adjusted regressions between weekly ICT use and interest in asking and receiving information were included. All data were analysed using SPSS version 22.0 software (SPSS Inc., Chicago, IL, USA). A value of less than 0.05 was considered significant for all tests.

\section{Results}

In total, 673 patients were enrolled in the survey (January 2015 to May 2016). The highest percentage of participants came from Ecuador (35.4\%) and Argentina (34.5\%), followed by Mexico (18.4\%), Peru (6.8\%) and Venezuela (4.9\%) (table S1). The mean age (SD) was 43.4 (20.18) years. The mean number of years that patients had the disease from the time of diagnosis was 15.2 (14.71) years. Over two-thirds of the participants were female (68.4\%) and the majority had an education level of high school (62.4\%) (table 1).

Internet access, owning a cell or smartphone

Of all Latin American asthmatic patients who were surveyed, the reported Internet access was 76.6\% (table 2). Patients with a university or postgraduate degree reported the highest rate of Internet access $(93.5 \%$, $\mathrm{p}<0.001$ ) (table S2). 


$\begin{array}{lc}\text { TABLE } 1 \text { Demographic information for the surveyed population } & \\ \text { Patients } & 673 \\ \text { Age } & \\ 12-18 \text { years (young) } & 95(14.1 \%) \\ 18-40 \text { years ladult) } & 217(32.2 \%) \\ >40 \text { years lold adult) } & 361(53.6 \%) \\ \text { Sex } & \\ \text { Male } & 213(31.6 \%) \\ \text { Female } & 460(68.4 \%) \\ \text { Race } & 270(40.1 \%) \\ \text { White } & 8(1.2 \%) \\ \text { Native } & 375(55.7 \%) \\ \text { Hispanic/mestizo } & 9(1.3 \%) \\ \text { Black } & 2(0.3 \%) \\ \text { Other } & \\ \text { Educational level } & 132(19.6 \%) \\ \text { No education/elementary } & 288(42.8 \%) \\ \text { High school } & 252(37.4 \%) \\ \text { University/postgraduate } & \\ \text { Time with asthma } & 201(29.9 \%) \\ 0-5 \text { years } & 446(66.3 \%) \\ >5 \text { years } & \end{array}$

In general, the percentage of patients who owned a cellphone was high (91.2\%) (table 2). The percentage of patients who owned a smartphone was 59.5\% ( $\mathrm{p}<0.001)$ (table 2$)$. Only $6.09 \%$ of the sample neither owned a cellphone nor had access to the Internet.

Use of ICTs at least once a week

The most used ICT form was SMS (69.9\%), followed closely by the Internet (56.8\%), Facebook (51.4\%) and E-mail (47.9\%) (table 2). Interestingly, YouTube was used by $33 \%$ of the patients.

A higher proportion of males used Facebook (60.4\%), YouTube (44.4\%), E-mail (56.6\%) and the Internet (67.4\%) when compared to females (table S3). Analysis by age shows that adults are associated with the highest rate of usage for every ICT form (table 2). $65.8 \%$ of old adults and $79.7 \%$ of adults use SMS at least once a week, while only $61.2 \%$ of young patients use it. Beyond this, old adults reported the lowest rates of using the other technologies $(\mathrm{p}<0.001$; table 2$)$. Remarkably, patients with the highest educational degree reported the highest rates for using all ICTs $(\mathrm{p}<0.001$; table S2).

\section{Use of ICTs for looking at information about asthma}

The participants used the Internet (41.5\%) and E-mail (13.6\%) most of all to seek information about asthma (table 2). It was found that more males use the Internet $(50.5 \%)$ and E-mail (18.1\%) than females when searching for information about their disease (table S3). When one considers age, the youngest individuals reported the highest rates of looking for information with the Internet (56.2\%), E-mail (16.9\%) and Facebook $(16.4 \%, \mathrm{p}<0.01)$. Patients with the highest educational level (university or postgraduate degree) reported the highest rates for finding of information through the Internet $(52.7 \%)$ and YouTube $(12.7 \%, \mathrm{p}<0.01)($ table S2).

High interest in receiving information using ICTS

WhatsApp (61.5\%), SMS (58.5\%), E-mail (43.6\%) and Facebook (32.0\%) were rated as the most interesting channels of communication for receiving information about the disease (table 2). A greater proportion of females recorded a high interest in receiving information (65.3\%) in comparison to males (table S2). Analysis by age reveals that adults reported the highest rates for receiving information through WhatsApp (76.8\%), E-mail (59.3\%) and Facebook (47.3\%, p<0.001; table 2). Finally, patients with a higher level of education reported a more frequent use of ICTs than those with a lower education level $(\mathrm{p}<0.001$; table S2).

High interest in asking physicians for information using ICT

SMS, WhatsApp, E-mail and Facebook were rated most highly when it came to asking physicians for information (scoring $60.0 \%, 58.4 \%, 41.5 \%$ and $30.4 \%$, respectively; table 2 ). A higher proportion of females also reported a high interest in asking for information about asthma from their physicians by SMS (66.9\%) 


\begin{tabular}{|c|c|c|c|c|c|}
\hline & Young & Adult & Old adult & $\begin{array}{c}\text { Chi-squared } \\
\text { p-value }\end{array}$ & Total \\
\hline Patients & 95 & 217 & 391 & & 673 \\
\hline \multicolumn{6}{|l|}{ Having } \\
\hline Internet access & $94.3 \%$ & $92.6 \%$ & $61.4 \%$ & $<0.001$ & $76.6 \%$ \\
\hline A cell phone & $94.4 \%$ & $97.3 \%$ & $86.4 \%$ & $<0.001$ & $91.2 \%$ \\
\hline A smartphone & $69 \%$ & $78.6 \%$ & $44.3 \%$ & $<0.001$ & $59.5 \%$ \\
\hline \multicolumn{6}{|c|}{ Use of ICT type (at least once a week) } \\
\hline SMS & $61.2 \%$ & $79.7 \%$ & $65.8 \%$ & 0.001 & $69.9 \%$ \\
\hline Facebook & $60 \%$ & $72.2 \%$ & $36.5 \%$ & $<0.001$ & $51.4 \%$ \\
\hline Twitter & $30.6 \%$ & $30.9 \%$ & $9.2 \%$ & $<0.001$ & $19.9 \%$ \\
\hline YouTube & $44.7 \%$ & $56.3 \%$ & $16.3 \%$ & $<0.001$ & $33.4 \%$ \\
\hline E-mail & $46.3 \%$ & $67.5 \%$ & $36.1 \%$ & $<0.001$ & $47.9 \%$ \\
\hline Internet & $64.6 \%$ & $74.6 \%$ & $44.4 \%$ & $<0.001$ & $56.8 \%$ \\
\hline Linkedln & $18.8 \%$ & $25 \%$ & $5.5 \%$ & $<0.001$ & $14.1 \%$ \\
\hline Skype & $25.4 \%$ & $30.1 \%$ & $8 \%$ & $<0.001$ & $18.1 \%$ \\
\hline \multicolumn{6}{|c|}{ Interest in receiving information through ICT type (high/some interest) } \\
\hline SMS & $51.2 \%$ & $58.2 \%$ & $60.5 \%$ & 0.322 & $58.5 \%$ \\
\hline Facebook & $43 \%$ & $47.3 \%$ & $19.6 \%$ & $<0.001$ & $32 \%$ \\
\hline Twitter & $31.3 \%$ & $19.4 \%$ & $2.4 \%$ & $<0.001$ & $11.6 \%$ \\
\hline Linkedln & $24.2 \%$ & $9.8 \%$ & $1.8 \%$ & $<0.001$ & $7.6 \%$ \\
\hline E-mail & $41 \%$ & $59.3 \%$ & $34.3 \%$ & $<0.001$ & $43.6 \%$ \\
\hline WhatsApp & $72.3 \%$ & $76.8 \%$ & $48.1 \%$ & $<0.001$ & $61.5 \%$ \\
\hline \multicolumn{6}{|c|}{ Interest in asking physician through ICT type (high/some interest) } \\
\hline SMS & $51.9 \%$ & $61.9 \%$ & $60.9 \%$ & 0.266 & $60 \%$ \\
\hline Facebook & $46.2 \%$ & $41.3 \%$ & $19.6 \%$ & $<0.001$ & $30.4 \%$ \\
\hline Twitter & $18.5 \%$ & $17 \%$ & $2.7 \%$ & $<0.001$ & $9.3 \%$ \\
\hline Linkedln & $20 \%$ & $10.8 \%$ & $2.2 \%$ & $<0.001$ & $7.5 \%$ \\
\hline E-mail & $37.7 \%$ & $56.4 \%$ & $33.1 \%$ & $<0.001$ & $41.5 \%$ \\
\hline WhatsApp & $69.5 \%$ & $74.9 \%$ & $44.2 \%$ & $<0.001$ & $58.4 \%$ \\
\hline
\end{tabular}

Differences in values between the three age groups are significant at the 0.05 significance level. SMS: short message service.

when compared to males (table S3). In addition, Facebook (46.2\%) was cited more by patients aged under 18 years; adults, in contrast, stated that they were more interested in asking a physician by E-mail (56.4\%) or WhatsApp (74.9\%, $\mathrm{p}<0.001$; table 2). Patients with the highest educational degree reported being more interested in asking physicians using these channels $(\mathrm{p}<0.001$; table S2).

\section{Logistic regression}

Females were more likely to be highly interested in receiving (OR 2.61) and asking (OR 2.55) physicians about asthma through SMS than their male counterparts (table 3).

All regressions for either young patients or young adults were reported as being above the unit (table S4). That is, older adults (reference category) always displayed the lowest preference for evaluation of every type of ICT, except for SMS. Overall, being a young individual (whether male or female) increases the likelihood of using every media form, except for SMS, when compared with older adults (table S4).

The odds of young patients using the Internet to look for information about asthma was recorded as being 2.52 times higher than that of older adults, and 2.82 times as high when it came to using YouTube (table S4). Both young and adult patients with asthma were found to display a higher interest in receiving information through Facebook (OR 2.75 and 2.90, respectively; table 3) and Twitter (OR 26.59 and 6.07 respectively) when compared to older adults. Such patterns also apply to the same ICT forms regarding interest in asking physicians questions. Young patients were also more likely to be highly interested in receiving (OR 3.16) and asking for information (OR 2.69) through WhatsApp than older adults (table 4). The same degree of likelihood is observed for adults (OR 2.54 and 2.67 respectively).

Analysis by education revealed patients who possessed the highest degree level to be 11.73 and 3.22 times (respectively) more highly interested in receiving information by E-mail and Facebook than the lowest 


\begin{tabular}{|c|c|c|}
\hline & $\begin{array}{l}\text { Interest in receiving information } \\
\text { through ICT type }\end{array}$ & $\begin{array}{l}\text { Interest in asking questions to } \\
\text { physicians through ICT type }\end{array}$ \\
\hline \multicolumn{3}{|l|}{ SMS (n=348) } \\
\hline \multicolumn{3}{|l|}{ Sex $\#$} \\
\hline Female & $2.61(1.78-3.79)$ & $2.55(1.76-3.69)$ \\
\hline Weekly SMS use ${ }^{\pi}$ & $1.81(1.27-2.60)$ & $2.57(1.78-3.69)$ \\
\hline \multicolumn{3}{|l|}{ Facebook $(n=307)$} \\
\hline \multicolumn{3}{|l|}{$\mathrm{Age}^{+}$} \\
\hline Young & $2.75(1.51-5.00)$ & $3.69(2.05-6.65)$ \\
\hline Adult & $2.90(1.88-4.48)$ & $2.45(1.58-3.80)$ \\
\hline \multicolumn{3}{|l|}{ Education level ${ }^{\S}$} \\
\hline University/postgraduate & $3.22(1.66-6.26)$ & $2.05(1.11-3.78)$ \\
\hline Weekly Facebook use & 12.58 (7.73-20.47) & 12.04 (7.34-19.75) \\
\hline \multicolumn{3}{|l|}{ E-mail (n=287) } \\
\hline \multicolumn{3}{|l|}{$\mathrm{Age}^{+}$} \\
\hline Adult & $1.63(1.08-2.45)$ & $1.67(1.11-2.49)$ \\
\hline \multicolumn{3}{|l|}{ Education level $^{\S}$} \\
\hline University/postgraduate & $11.73(6.06-22.69)$ & $8.66(4.61-16.25)$ \\
\hline Weekly E-mail use & 12.04 (8.06-17.98) & $13.48(8.90-20.43)$ \\
\hline \multicolumn{3}{|c|}{$\begin{array}{l}\text { Data are presented as OR }(95 \% \text { CI). The regression analysis was adjusted for variables such as age, sex, } \\
\text { educational level and duration of time with asthma since diagnosis. Regression analyses using weekly ICT } \\
\text { types were performed separately (non-adjusted). All values displayed are significant at the } 0.05 \\
\text { significance level. SMS: short message service. }{ }^{\#}: \text { reference sex is male; }{ }^{\text {I }} \text { : reference ICT use is less than } \\
\text { once a week; }{ }^{+}: \text {reference age category is old adult; }{ }^{\S} \text { : reference educational level category is no } \\
\text { education/elementary. }\end{array}$} \\
\hline
\end{tabular}

degree level (reference category) (table 3). Patients with the highest degree and high-school level were respectively 8.66 and 3.01 times more likely to be highly interested in asking physicians about asthma through E-mail than the reference (table 3). Furthermore, the sample of patients with the highest level of education was 3.79 and 4.26 times (respectively) more interested in receiving and asking for information through WhatsApp than the lowest education level group (table 4).

If an individual indicated little or no interest in using an ICT form to communicate with their physician, we included open-ended questions to allow them to explain the reasons why. However, most of the patients $(62.3 \%)$ did not give a reason why they were not interested in using ICTs for these purposes. Among those patients that shared an opinion, 27.6\% reported that they either did not have accounts for these media or did not know how to use them. Many subjects explained that they did not use ICTs frequently, so they thought they would not be able to communicate effectively with physicians. Several people preferred to communicate directly with their physician through phone calls or by meeting them in person. Finally, some patients manifested their discomfort using these ICTs by saying that they wanted to keep their health status private from their social circle.

\section{Discussion}

With the increasing and widespread use and demand for ICT apps, it is important to determine which technologies might be most effective in improving asthma and medical outcomes. As far as electronic means are concerned, the use of smartphones has grown rapidly in Latin America [20]. A recent publication determined that $43.4 \%$ of all Latin American households were connected to the Internet in 2015; this is nearly double the figure for 2010 [21]. The present study showed that a great proportion of asthmatic patients had access to the Internet and were thus theoretically capable of benefitting from this technological tool. More than half had a smartphone, although the proportion of owners differed among the countries surveyed. The Internet was used by large numbers of patients to search for information about asthma (41.5\%), and this proportion increased with age and the higher level of education of the patients.

A previous study found E-mail and SMS to be the most popular forms of electronic communication for receiving and seeking information among asthmatic patients [12]. Our results suggest that SMS and E-mail are both useful tools for communicating (i.e. receiving and seeking information) with all asthma patients, 


\begin{tabular}{|c|c|c|}
\hline Variable & $\begin{array}{l}\text { Interest in receiving information } \\
\text { through WhatsApp }\end{array}$ & $\begin{array}{l}\text { Interest in asking physicians } \\
\text { through WhatsApp }\end{array}$ \\
\hline \multicolumn{3}{|l|}{$\operatorname{Age}^{\#}$} \\
\hline Young & $3.16(1.17-5.82)$ & $2.69(1.49-4.85)$ \\
\hline \multicolumn{3}{|l|}{ Education level ${ }^{\text {ๆ }}$} \\
\hline University/postgraduate & $3.79(2.20-6.54)$ & $4.26(2.43-7.47)$ \\
\hline
\end{tabular}

regardless of age and particularly among Ecuadorian patients. We obtained similar findings, but SMS was generally preferable to E-mail.

There are several practical reasons for using SMS. It costs less than voice messaging and it can reach people whose phones are switched off at the time of sending. Furthermore, SMS messaging is silent, which means that messages can be sent and received in places where it may be impractical to hold a conversation [22]. Usually, personal health information may also be best communicated in these ways for privacy reasons [23]. A meta-analysis recently concluded that mobile phone text messaging had the capacity to double the likelihood of medication adherence [24].

A recent publication found that adolescents and young adults have limited interest in health information shared on social media, and that these platforms are not useful for learning about health and they do not want to connect by these means with their physicians [25]. These findings may limit the utility of ICT initiatives to improve health in young people [25]. In contrast, we found that young patients with asthma have a high interest in receiving information and directing questions to their physicians through both Facebook (OR 2.75 and OR 3.69, respectively) and Twitter (OR 26.59 and OR 12.21, respectively) when compared to old adults. Consistent with our findings, some evidence has suggested that younger audiences are more likely to use electronic technologies and are more interested in their use for health interventions than older audiences [26].

During 2015, Facebook was the most popular social media site in the USA [27]. In Latin America, 32.14\% of people use Facebook [28]. The results of the present study are consistent with the above findings and may be applicable to a wider population in Latin America.

With age generations categorised as baby boomers, generation $\mathrm{X}$, generation $\mathrm{Y}$ (millennials) and generation $\mathrm{Z}[29,30]$, previous studies determined that members of generation $\mathrm{X}$ (i.e. those who are currently over 40 years old) are statistically more likely to use Twitter than younger generations [31]. The results of the present study disagree with this finding, because Latin American asthmatics aged over 40 years are less active on Twitter in obtaining or seeking out information about their disease. Our results suggest that young asthma patients are more likely to be highly interested in receiving information (OR 26.59) and directing questions to their physician (OR 12.21) by Twitter than generation $X$ patients. We did not examine if young asthmatic patients were interested in publicising and promoting their own discoveries of health information, e.g. by gathering followers and being re-tweeted.

The bottom line is that young patients with asthma show a high interest in receiving information and communicating with their physician through Facebook and Twitter. In fact, in another publication, Hispanic patients believed their health providers should use Facebook and Twitter to share health information [32].

WhatsApp is a cross-platform instant messaging app that allows smartphone users to exchange text, image, video and audio messages for free. In Latin America, around two-thirds of Internet users are now "WhatsApping", in contrast with North Americans, who have a somewhat lower frequency of use of WhatsApp [33]. Our results suggest that WhatsApp could be appropriate for patients in the age category 12-40 years. Because of the different categories of interest used in analysis for WhatsApp and other electronic networks, they cannot be compared directly. However, we found that young respondents were willing to use WhatsApp to receive information (OR 3.16) and direct questions to their physicians (OR 2.69) about asthma. In Latin America, some mobile operators currently offer different plans that include 
non-limited data usage exclusively for WhatsApp and Facebook services. This is probably at least one reason why Latin America has a high Internet penetration rate compared with other global regions.

In a previous study, females were more likely than males to be interested in using ICTs for asthma care

[16]. In contrast, we found that males use more ICTs for this purpose, although in our study the majority were female. However, females notably show a higher interest than males in sending questions to their physicians through SMS.

Our results have important implications for designing interventions using ICT platforms. To improve patient education and communication between healthcare professionals and patients, it is possible, indeed advantageous, to use E-mail, SMS and the Internet for all age groups. However, other social media, such as Twitter, Facebook and WhatsApp, are becoming increasingly popular among patients aged under 40 years. We found that being young and having the highest education level are the main factors associated with frequent media use as well as showing a high interest in using them for all purposes. Our results showed a significant p-value $(<0.05)$ in almost all cases.

There is a significant difference in the utilisation of different forms of health information technologies tools between rural and urban areas [34]. In Latin America there are research projects about which appropriate technologies provide the best communication [35]. Our study presents data that could be used to develop new applications or uses of social media with a view to improving asthma outcomes in Latin America.

For instance, new technologies may help reach patients who are physically difficult to reach, such as those living in inner cities or rural areas and those with poorly controlled asthma. Such technologies can therefore achieve better outcomes. This type of intervention has the additional advantage of having the potential to be highly personalised, based on the individual participant's data and engaging with interactive tools and graphically rich content. The appropriate use of ICT can bring about notable benefits and improvements to current practice, such as support from healthcare professionals and peers for children and adolescents with asthma. This would in turn enable them and their families to overcome some of their feelings of social isolation. Medical apps for patients are software programs that run on personal mobile devices and offer functions such as disease tracking, access to clinical and peer support, health information and reminders [36].

By 2015, 209 mobile health apps had been developed to improve asthma control [15]. In a recent meta-analysis about the evolution of mobile apps for asthma, over a quarter of apps included in the original review had been withdrawn. Unexpected withdrawal of an app may be an inconvenience for individual users. Our results could enhance understanding preferences on the part of the patient and should facilitate the development of applications that can best improve asthma outcomes.

Our study has some limitations. First, this is a cross-sectional study and therefore cause-and-effect relationships cannot be made. Second, it was not conducted in all Latin American countries and the preferred use of social media in other countries could differ significantly. Third, almost $70 \%$ of the respondents were female, so our findings are not so easily generalisable to males. Also, our participants knew the purpose of the study, which may have affected the answers that some of them gave. Finally, the Michigan survey has not been validated and our results could lead to biased or inaccurate conclusions. On the other hand, one strength of this study is that it covered a good sample size $(n=673)$ of asthmatics. The sample also included participants of different age, sex and educational level. Future research is needed to confirm our findings and assess the real use of ICT.

Randomised trials will of course be necessary to determine the efficacy and cost-effectiveness of all new ICT tools in promoting asthma control among patients. We also need to examine the benefit for asthma patients. However, the widespread use of ICTs today opens new possibilities for the relationship between physicians and patients. Few published studies have evaluated the use of ICT for healthcare purposes among Hispanic patients, and this can also be included as a desideratum within the field [37].

Finally, we can assert with confidence, following our results, that WhatsApp is an interesting new communication channel, because it was highly favoured by our participants, especially young people. Patients in Mexico and Venezuela reported higher use of this channel than other countries.

\section{Conclusion}

A rich variety of ICT forms are becoming universal in modern medical practice. There is a rapid growth and turnover in the utilisation of ICT for asthma care and communication. The findings of the present study are relevant because they indicate that SMS would be useful among all ages, while Facebook, WhatsApp and Twitter would be useful in young and adult patients among Latin American asthmatics. As for the patients' level of education, Latin American patients with asthma and a higher educational level 
tended to be more interested in communicating by ICT. It may be possible to develop applications in response to the specific requirements of each patient in different countries. Future research is needed to examine the specific nature of the benefits for asthma patients and to identify ways that these benefits can be particularised to specific audience groups. However, it is indisputable that the widespread use of social media is opening new possibilities for the relationship between physicians and patients, improving communication in both directions.

\section{Acknowledgements}

I. Cherrez Ojeda is a candidate at the Doctorate Program of Biomedical Research and Public Health, Universitat Autonoma de Barcelona, Barcelona, Spain.

The authors acknowledge the guidance and knowledge imparted by the MECOR Program for this study, especially from Sonia Buist MD and Ana Menezes MD. The authors are grateful for the support provided by Gabriela Martinetti, Michell Torres, José Cano, Karin Plaza and Linda Vera, as well as all members of the RespiraLab team.

\section{References}

1 Moorman JE, Akinbami LJ, Bailey CM, et al. National surveillance of asthma: United States, 2001-2010. Vital Health Statist 2012; 35: 1-58.

2 Mallol J, Sole D, Baeza-Bacab M, et al. Regional variation in asthma symptom prevalence in Latin American children. J Asthma 2010; 47: 644-650.

3 Dennis RJ, Caraballo L, Garcia E, et al. Prevalence of asthma and other allergic conditions in Colombia 2009-2010: a cross-sectional study. BMC Pulm Med 2012; 12: 17.

4 Garcia-Sancho C, Fernandez-Plata R, Martinez-Briseno D, et al. Adult asthma in Mexico City: a population-based study. Salud Publica Mex 2012; 54: 425-432.

5 Buse DC, Lipton RB. Facilitating communication with patients for improved migraine outcomes. Curr Pain Headache Rep 2008; 12: 230-236.

6 Bender B. Physician-patient communication as a tool that can change adherence. Ann Allergy Asthma Immunol 2009; 103: 1-2.

7 Newcomb PA, McGrath KW, Covington JK, et al. Barriers to patient-clinician collaboration in asthma management: the patient experience. J Asthma 2010; 47: 192-197.

8 Perron BE, Taylor HO, Glass JE, et al. Information and communication technologies in social work. $A d v$ Soc Work 2010; 11: 67-81.

9 Van den Bulck J. Adolescent use of mobile phones for calling and for sending text messages after lights out: results from a prospective cohort study with a one-year follow-up. Sleep 2007; 30: 1220.

10 Farmer AD, Holt CB, Cook M, et al. Social networking sites: a novel portal for communication. Postgrad Med J 2009; 85: 455-459.

11 Lombardi C, Passalacqua G, Canonica GW. The WEB-based Asthma Control: an intriguing connection or a dangerous hazard? Asthma Res Pract 2015; 1: 15.

12 Baptist AP, Thompson M, Grossman KS, et al. Social media, text messaging, and email-preferences of asthma patients between 12 and 40 years old. J Asthma 2011; 48: 824-830.

13 Hui CY, Walton R, McKinstry B, et al. The use of mobile applications to support self-management for people with asthma: a systematic review of controlled studies to identify features associated with clinical effectiveness and adherence. I Am Med Inform Assoc 2016; 24: 619-632.

14 Krebs P, Duncan DT. Health app use among US mobile phone owners: a national survey. JMIR mHealth uHealth 2015; 3: e101.

15 Wu AC, Carpenter JF, Himes BE. Mobile health applications for asthma. J Allergy Clin Immunol Pract 2015; 3 446-448.

16 Huckvale K, Morrison C, Ouyang J, et al. The evolution of mobile apps for asthma: an updated systematic assessment of content and tools. BMC Med 2015; 13: 58.

17 Belisario M, Huckvale K, Greenfield G, et al. Smartphone and tablet self management apps for asthma. Cochrane Database Syst Rev 2013; 11: CD010013.

18 Fox S, Duggan M. Health Online 2013. Washington, Pew Research Center, 2013.

19 Sperber AD. Translation and validation of study instruments for cross-cultural research. Gastroenterology 2004; 126: Suppl. 1, S124-S128.

20 Smith A. US Smartphone Use in 2015. Washington, Pew Research Center, 2015.

21 NU CEPAL. State of broadband in Latin America and the Caribbean 2016 [Estado de la banda ancha en América Latina y el Caribe 2016]. www.cepal.org/es/publicaciones/40528-estado-la-banda-ancha-america-latina-caribe-2016 Date last updated: October 2016.

22 Kaplan WA. Can the ubiquitous power of mobile phones be used to improve health outcomes in developing countries? Global Health 2006; 2: 9.

23 Chretien KC, Kind T. Social media and clinical care. Circulation 2013; 127: 1413-1421.

24 Thakkar J, Kurup R, Laba T-L, et al. Mobile telephone text messaging for medication adherence in chronic disease: a meta-analysis. JAMA Intern Med 2016; 176: 340-349.

25 Hausmann JS, Touloumtzis C, White MT, et al. Adolescent and young adult use of social media for health and its implications. J Adolesc Health 2017; 60: 714-719.

26 Chou W-YS, Hunt YM, Beckjord EB, et al. Social media use in the United States: implications for health communication. J Med Internet Res 2009; 11: e48.

27 Duggan M. Mobile Messaging and Social Media 2015. Washington, Pew Research Center, 2015.

28 Henostroza W. Estadísticas de Facebook en Latinoamérica y España Perú. 2011. www.webespacio.com/ facebook-latinoamerica-espana-analisis-estadisticas/

29 Tapscott D. Grown Up Digital: How the Net Generation is Changing Your World. New York, McGraw-Hill Education, 2008 
Friedrich R, Peterson M, Koster A, et al. The Rise of Generation C Implications for the World of 2020. New York, Booz \& Company, 2010.

31 Fietkiewicz KJ, Lins E, Baran KS, et al. Inter-Generational Comparison of Social Media Use: Investigating the Online Behavior of Different Generational Cohorts. http://ieeexplore.ieee.org/abstract/document/7427661/ Date last updated: March 10, 2016.

32 Hanson CL, West J, Thackeray R, et al. Understanding and predicting social media use among community health center patients: a cross-sectional survey. J Med Internet Res 2014; 16: e270.

33 Whatsapp Usage Highest in LatAm. www.globalwebindex.net/blog/whatsapp-usage-highest-in-latam?utm_ campaign=COTD\&utm_content $=26870755 \& u t m \_$medium $=$social\&utm_source $=$twitter Date last updated: January 29, 2016.

34 Greenberg AJ, Haney D, Blake KD, et al. Differences in access to and use of electronic personal health information between rural and urban residents in the United States. J Rural Health 2016 [in press https://doi.org/ 10.1111/jrh.12228].

35 Prieto-Egido I, Simó-Reigadas J, Liñán-Benítez L, et al. Telemedicine networks of EHAS foundation in Latin America. Front Public Health 2014; 2: 44-52.

36 Klasnja P, Pratt W. Healthcare in the pocket: mapping the space of mobile-phone health interventions. J Biomed Inform 2012; 45: 184-198.

37 Justice-Gardiner H, Nutt S, Rechis R, et al. Using new media to reach Hispanic/Latino cancer survivors. J Cancer Educ 2012; 27: 100-104. 